\title{
Thermoeconomic Analyses of Steam Injected Gas Turbine Cogeneration Cycles
}

\author{
R. KARAALI ${ }^{a, *}$ AND I.T. ÖZTÜRK ${ }^{b}$ \\ ${ }^{a}$ Department of Mechanical Engineering, Bayburt University, 69000 Bayburt, Turkey \\ ${ }^{b}$ Department of Mechanical Engineering, Kocaeli University, Umuttepe 41380, Kocaeli, Turkey
}

\begin{abstract}
In this study, three different gas turbine cogeneration systems that are preheating air, preheating air-fuel and simple cycles where steam injected in to combustion chamber are analyzed. The effects of steam injection on thermoeconomic performance are calculated and obtained. By using the first law of thermodynamics, the exergy analysis and economic methods, simulation programs written by the authors in FORTRAN code are obtained to use for the analyses. Thermoeconomic performance of these three different cycles for different stage and variable mass of injected steam are obtained and compared with literature. The effects of injection steam in to combustion chambers of those three cycles for variable compressing ratios, on power, efficiencies, product price and performances are obtained. Consequently, the advantages and the disadvantages of injection steam are evaluated. The results obtained in this study are compared with the results available in the literature. Injection steam into combustion chamber increases the electricity efficiency and electricity power but decreases the heat power of the cycles. Also the produced electricity price for per kWh is increasing.
\end{abstract}

DOI: 10.12693/APhysPolA.128.B-279

PACS: 88.20.tf, 88.05.Lg, 88.05.-b

\section{Introduction}

In analyzing thermal and cogeneration plants thermoeconomic methods, where economic and exergy methods are combined are found to be more effective and more appropriate than the conventional methods. This method provides detailed insight about the solutions. In designing thermal cycles, thermoeconomic analysis is very important to understand the characteristics of cycles economically and thermodynamically. Thermoeconomic methods allow us to understand and to trace the cost flow, and exergy destruction in the components of the cycles. In thermoeconomic analysis algebraic and calculus methods have been heavily employed. By using the algebraic thermoeconomic methods, the average costs can be obtained by solving cost equations for each component. Marginal and exergetic costs can be calculated by modeling each stream and component with differential equations which is called calculus methods. Thermoeconomic methods are mainly the thermoeconomic functional analysis, the exergetic cost theory, the thermoeconomic evaluation and optimization, and the engineering functional analysis methods. There are two groups of approaches in formulating auxiliary costing efficiencies and equations [1]. The first one is the exergoeconomic accounting methods that use iterative optimization of the system or devices. The second one is the Lagrangian based approaches which aim the optimization of the overall system. Thermoeconomic analysis should aim exergy streams costs, each product cost, and entropy generation [2]. In our analysis, the cost levelization approach is

*corresponding author; e-mail: rabikar@gmail.com used to determine the cost variation with time. Karaali and Ozturk have introduced a novel simple and efficient thermoeconomic optimization method for real complex cycles by improving the non-linear simplex direct search method. They have analyzed, compared and discussed the local and the global thermoeconomic optima of the costs and they have found the electricity costs at local optima are higher than the global optima. The details of the thermoeconomic analyses and optimization methods can be found in literature $[1,3,4]$.

In gas turbine cogeneration systems, the air are compressed in a compressor and then a liquid petroleum product or gaseous fuel in the combustion chamber is burned to obtain exhaust gas at temperature about 900 $1500^{\circ} \mathrm{C}$. The exhaust gas of the outlet of the combustion chamber gives some of its energy to the turbine to produce electricity while the turbine outlet gas temperature falls between 500 or $900^{\circ} \mathrm{C}$. Exhaust gas of the turbine outlet produces steam or hot water in the heat recovery steam generator [5]. In the 1980s, because of the increasing need of heat and power, the gas turbine cogeneration systems became widespread in the industry. Changing the electricity and heat demand increased the interest of the gas turbine systems and that has led to coming up these days. Steam injection into the combustion chamber began in the 1950s, and today to minimize the compounds of NOx this method is used. Since the 1980s, the thermoeconomic analysis of thermal plants has been started by many researchers, however thermoeconomic analysis of steam injected cogeneration plants are very few in literature $[6,7]$.

The cycles that are analyzed thermoeconomically in this study are shown in Fig. 1. Fig. 1c shows the air-fuel preheated cycle that the fuel in another recuperator is heated by the exhaust gases energy to increase the fuel 
temperature. In this study, three steam injected gas turbine cogeneration systems such as simple (si), air preheating (ap), and air-fuel preheating (afp) cycles are analyzed by using thermoeconomic analysis method.
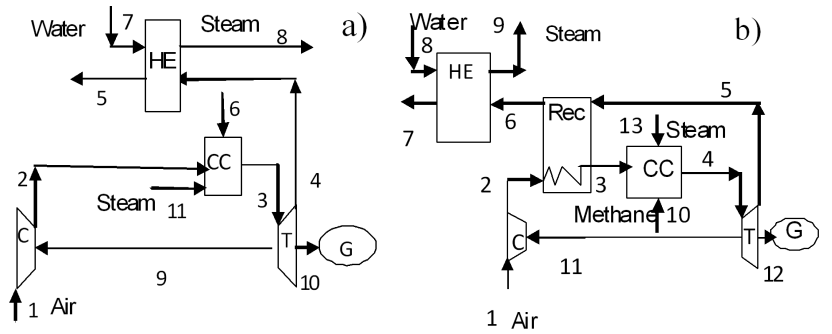

c)

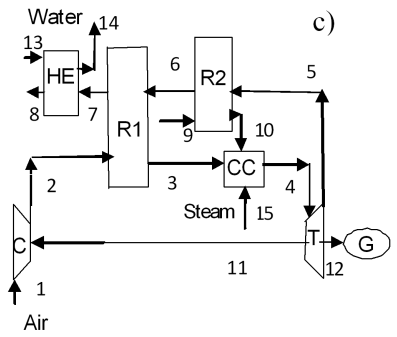

Fig. 1. Steam injection into the combustion chamber of a) simple b) air preheated c) air-fuel preheated cycles.

In addition, thermodynamic evaluation of the three cycles are studied and compared. The most important parameters of a steam injected gas turbine cogeneration system such as electric cost, exergetic efficiency, electric and heat power are analyzed and compared with each others.

\section{Materials and methods}

Thermoeconomic model of gas turbine cogeneration cycle can be written as follows [8]: the first law of thermodynamics by neglecting potential and kinetic energy changes can be written as,

$$
\sum_{C} \dot{Q}-\sum_{C} \dot{W}=\Delta H
$$

the enthalpy change can be written as

$$
h_{2}-h_{1}=\int_{1}^{2} c_{p 0} \mathrm{~d} T \text {. }
$$

Combustion reaction assumed to be ideal and the natural gas has been accepted as methane. Stoichiometric combustion of the fuel is given as,

$$
\begin{gathered}
\mathrm{CH}_{4}+2\left(3.763 \mathrm{~N}_{2}+\mathrm{O}_{2}+0.00146 \mathrm{CO}_{2}+0.09228 \mathrm{H}_{2} \mathrm{O}\right) \\
\leftarrow 7.526 \mathrm{~N}_{2}+1.002914 \mathrm{CO}_{2}+2.184556 \mathrm{H}_{2} \mathrm{O} .
\end{gathered}
$$

Exergy of flow is calculated with the help of the following relation [4]:

$$
\begin{aligned}
& E_{\mathrm{phys}}=\dot{m}\left[\left(h-h_{0}\right)_{\mathrm{mix}}-T_{0}\left(s-s_{0}\right)_{\mathrm{mix}}\right], \\
& E_{\text {chem }}=\sum_{i} y_{i} E_{\mathrm{chem}, i}+\dot{m} R T_{0} \sum_{i} y_{i} \ln y_{i},
\end{aligned}
$$

$$
E=E_{\text {phys }}+E_{\text {chem }} .
$$

The exergy efficiency can be written as follows [4]

$$
\eta_{e x}=\frac{W+E_{Q}}{E_{\text {fuel }}} \text {. }
$$

The revenue requirement method is applied for the main product cost calculation and for economic analysis of the thermal systems. The basic four steps of the method employed in this studyhird step the total revenue requirement is calculated, and the last step is the levelized product cost calculation. Estimation of the total capital investment is a one-time cost that includes the fixed capital investment. The fixed capital investment has the direct and the indirect costs elements. For cost estimation of the purchased equipment three methods are used: cost estimating charts, cost indices, and calculation effect of size on equipment which is used in this study [9]. The cost balance for the overall system operating at steady state is given by

$$
\dot{C}_{P, \text { tot }}=\dot{C}_{f, \text { tot }}+\dot{Z}_{\text {tot }}^{C I}+\dot{Z}_{\text {tot }}^{O M} \text {. }
$$

In this equation $C$ is cost rate, $Z$ is non exergy related cost rate, $C I$ is capital investment, $f$ is fuel, $P$ is product, tot is total and $O M$ is operating and maintenance.

\section{Results and discussions}

Variations of electric power with injected steam rate for different values of the compression rate are given in Fig. 2. As can be concluded that, increasing the injected steam rate increases the electric power of the cycles. Variations of heat exergy power with injected steam rate for different values of the compression rate are given in Fig. 3. Increasing the injected steam rate decreases

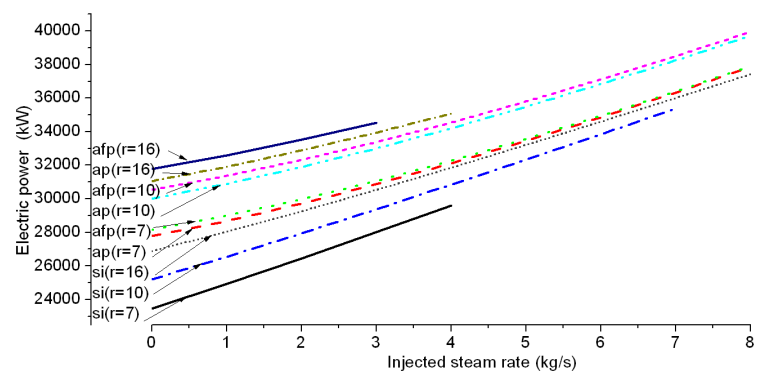

Fig. 2. Electric power vs. injected steam rate.

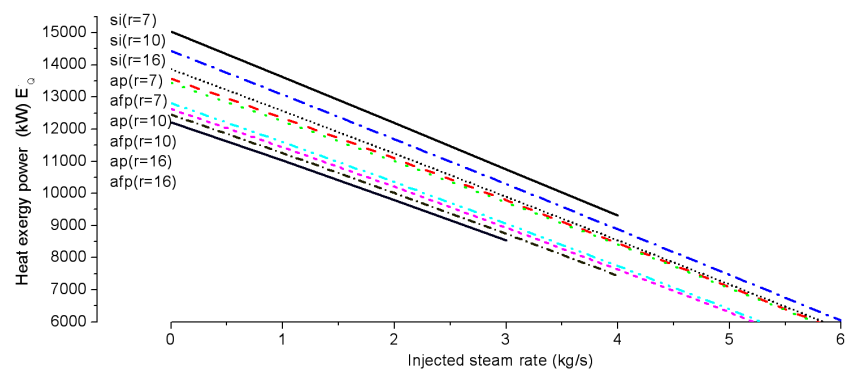

Fig. 3. Heat exergy power vs. injected steam rate. 


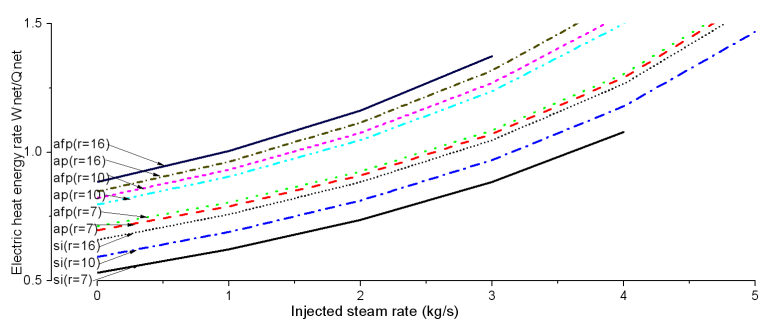

Fig. 4. Electric heat energy rate vs. injected steam rate.

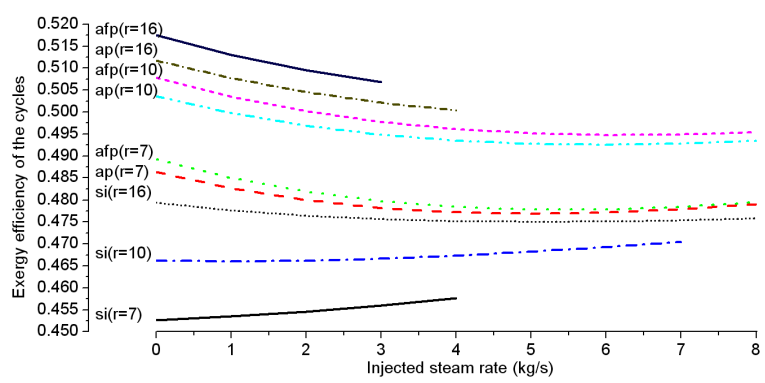

Fig. 5. Total exergy power vs. injected steam rate.

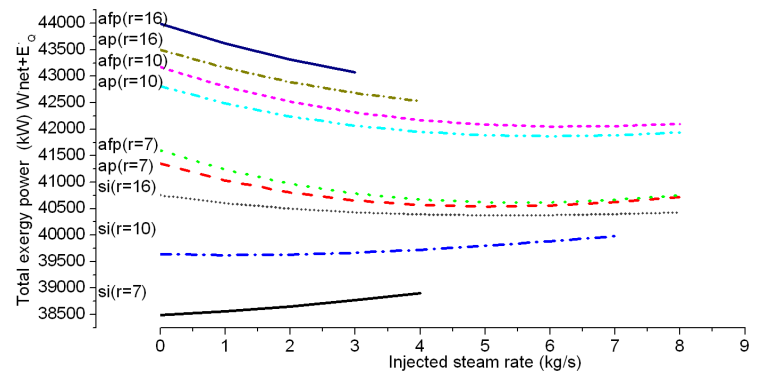

Fig. 6. Exergy efficiency vs. injected steam rate.

the heat exergy power which that is the result of using the steam in the combustion. Variations of electric heat energy rate with injected steam rate for different values of the compression rate are given in Fig. 4. As can be concluded that, increasing the injected steam rate increases the electric heat energy rate of the cycles. Variations of total exergy power with injected steam rate for different values of the compression rate are given in Fig. 5 . Increasing the injected steam rate decreases the total exergy power of the cycles except the simple cycles' low compression ratios.

Variations of exergy efficiency with injected steam rate for different values of the compression rate are given in Fig. 6. As can be concluded that, increasing the injected steam rate decreases the exergy efficiency except the simple cycles' low compression ratios. Variations of electricity cost with injected steam rate for different values of the compression rate are given in Fig. 7. Increasing the injected steam rate increases the electric cost of the cycles however decreasing compression rates decreases the electric cost.

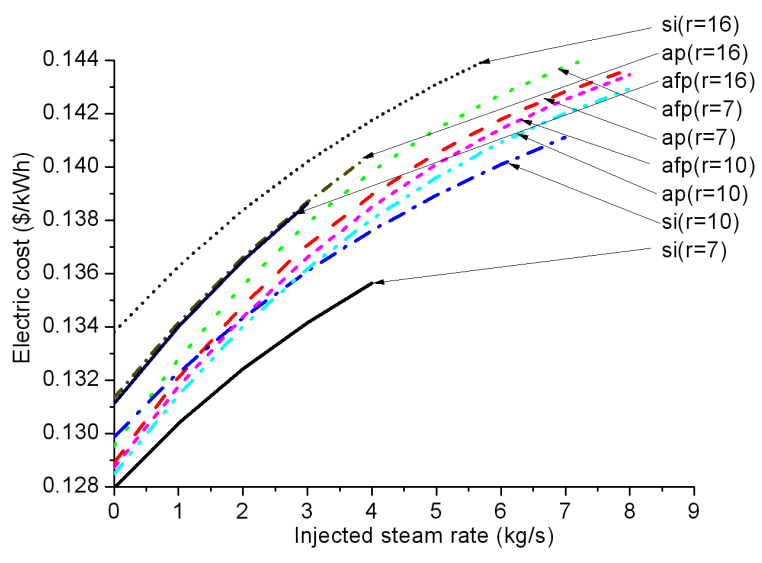

Fig. 7. Electricity cost vs. injected steam rate.

\section{Conclusion}

In this study, three different cycles are analyzed by using the thermoeconomic analysis method. It has seen that, increasing the compression ratio increases the electricity power however decreases the heat output. The steam injected is taken from the heat recovery steam generator, for that reason the heat output are decreasing. Increasing injected steam mass decreases the exergy of the cycles however increases the electric power. The exergy efficiency of the cycles decreases with increasing injected steam mass. However increasing injected steam mass increases the exergy efficiency of the simple cycle in low compression rates. Injection steam into the cycle's combustion chambers increases the electric cost. The reason is more injection steam means less heat power because of using the steam produced in the HRSG. In this way the steam can be used to increase the electric power. As the result, the steam injection method is an ideal method to apply where steam is not needed.

\section{References}

[1] D.J. Kim, Energy 35, 410 (2010).

[2] A. Agudelo, A. Valero, C. Torres, Energy 45, 634 (2012).

[3] R. Karaali, I.T. Ozturk, Energy 80, 474 (2015).

[4] A. Bejan, G. Tsatsaronis, M. Moran, Thermal Design and Optimization, Wiley, 1996.

[5] J.H. Horlock, Cogeneration-Combined Heat and Power (CHP), Crieger, 1997.

[6] M. Jonsson, J. Yan, Energy 30, 1013 (2005).

[7] W.D. Paepe, F. Delattin, S. Bram, J.D. Ruyck, Appl. Energ. 97, 569 (2012).

[8] A. Lazzaretto, G. Tsatsaronis, Energy 31, 1257 (2006).

[9] Nye Thermodynamics Corporation, Gas Turbine Prices by Output, 2014 